DOI 10.20396/temáticas.v1i1/2.11215

\title{
A Sociologia dos Bens Simbóllicos e a TeOria do Mercado Lingứstico DE PierRe BourdieU
}

\section{Inês Sívia Vitorino Sampaio}

Este artigo constitui um exercício de reflexão sobre a obra de Pierre Bourdieu, um dos autores contemporâneos que tem se destacado na análise dos sistemas simbólicos e no desenvolvimento da sociologia da cultura. A apropriação, aqui registrada, da sua obra resulta de um primeiro contato mais sistemático com o seu trabalho. Na verdade, a nossa atenção dirige-se especialmente às suas reflexões acerca da temática da linguagem. Nesse sentido, o esforço empreendido, de dar conta das proposiçōes de caráter mais geral da sua obra, é feito a partir do interesse em compreender, em que medida elas informavam a sua teoria dos mercados lingüísticos.

No enfrentamento da temática da linguagem, esboçamos ainda uma tentativa de análise comparativa das reflexões de Bourdieu com o pensamento de Jürgen Habermas. $O$ trabalho está centrado na obra de Bourdieu, sendo a referência ao pensamento habermasiano utilizada apenas como instrumento comparativo, o que explica o caráter sumarizado da sua exposição e a sıa menor problematização. $\mathrm{O}$ que estamos tentando salientar é que, foi exatamente a isso, que nos propomos.

Temáticas, Campinas, 1(1/2):189-227, jul./dez. 1993. 
Panorama Intelectual e Indagações Fundamentais

Discutir o pensamento de um autor significa aceitar o desafio de enfrentar com ele as discussões com as diferentes concepções teóricas que formam o panorama intelectual de uma época e que conferem um sentido à sua produção. Visto nessa perspectiva, Bourdieu é um teórico profundamente instigante, dada a ampla variedade de questões com que se defronta e o rigor conceitual com que busca apreendê-las.

$O$ contexto intelectual de Bourdieu é o da fenomenologia existencialista, que tem o seu auge, quando ainda era estudante nos anos 50 e também o do estruturalismo, dos anos 50/60, que se constitui com Lévi-Strauss na Antropologia, expande-se fortemente com a lingüística saussureana, atingindo ampla divulgação com os trabalhos de Foucault e Althusser, ambos professores de Bourdieu.

Sem nunca afirmar-se como fenomenólogo ou estruturalista, Bourdieu ergue o seu sistema analítico no debate sistemático com essas concepções. A idéia do debate, aqui registrada, tem como propósito recuperar a riqueza da relação estabelecida por Bourdieu com essas tradições e que não é pautada por uma postura meramente oposicional, nem tampouco identificatória, mas pela busca do diálogo, que incorpora e supera e, por isso mesmo, ultrapassa.

Esse é um elemento caracterizador da sua obra, a abertura para incorporar a contribuição dos diversos autores, sem se deter em oposições de escolas. Bourdieu destaca como um dos obstáculos graves ao processo de pesquisa a definição de "falsas antinomias" e "falsas divisões", que promovem oposições sem fundamento científico: teóricos $\mathrm{x}$ empiristas, subjetivistas $\mathbf{x}$ objetivistas, estruturalistas $\mathrm{x}$ fenomenólogos. Contrariamente a esse tipo de postura, Bourdieu postula a necessidade de uma "justa atitude para com a tradição teórica, que consiste em afirmar, ao mesmo tempo, a continuidade e a ruptura, a conservação e a superação, em se apoiar em

Temáticas, Campinas, 1(1/2):189-227, jul./dez. 1993. 
todo o pensamento disponivel, sem temer a acusação de seguidismo ou de ecletismo, para ir além dos antecessores, ultrapassados assim por uma utilização nova dos instrumentos para cuja produção eles contribuiram" ${ }^{1}$

No debate entre o estruturalismo e a fenomenologia, de relevância central para a configuração da sua obra, se atualizam distintas tradições da sociologia, que de forma recorrente reaparecem, sob novas roupagens, traduzindo o enfrentamento dos binômios, já clássicos, entre: indivíduo e sociedade, micro e macro, ator e estruturas. A Sociologia de Bourdieu se configura como uma tentativa de superar essas dicotomias.

Num período marcado pelo questionamento de vários dos paradigmas das ciências sociais, a sociologia de Bourdieu enfoca especialmente as várias formas de objetivismo (a postulação que desconsidera a subjetividade no processo de elaboração do conhecimento, estabelecendo uma rígida fronteira entre fatos e valores) e as várias versões estruturalistas (a postulação do primado das estruturas sobre os atores). A sua saída, contudo, difere radicalmente de qualquer forma de subjetivismo.

$\mathrm{Na}$ verdade, o enfrentamento do debate objetivismo $\mathrm{x}$ subjetivismo aparece em primeiro plano na sua obra, constituindo, segundo o próprio Bourdieu, a intenção mais constante e importante do seu trabalho. Bourdieu nega a tradição objetivista, que concebe o mundo social como um universo de regularidades objetivas, independente dos agentes e construído a partir do ponto de vista externo de um observador imparcial. Rejeita também a tradição fenomenológica que compreende o mundo social como produto das ações individuais, que a partir de infinitos atos produzem a objetividade das relações sociais, vinculando a análise às interpretações internas dos agentes.

${ }^{1}$ BOURDIEU, Pierre, $O$ poder simbólico, Ed. Difel, Lisboa, 1989, p. 63.

Temáticas, Campinas, 1(1/2):189-227, jul./dez. 1993. 
Segundo Bourdieu, seja na tradição durkheimiana que se propunha a apreender a sociedade como "coisa", seja no estruturalismo de Lévi-Strauss e Althusser, as análises partiam de um mesmo equívoco comprometedor, a compreensão do agente como mero executor de algo que lhe é exterior e que está objetivamente constituído. Este ponto de vista é explicitamente criticado por Bourdieu para quem "os agentes sociais, tanto nas sociedades arcaicas como nas nossas, não são apenas autômatos regulados como relógios, segundo leis mecânicas que lhes escapam". ${ }^{2}$

Nessa perspectiva, podemos afirmar que Bourdieu compartilha de toda a reflexão contemporânea nas ciências sociais que apregoa a imperiosa necessidade de trazer o ator de volta. E é de uma maneira muito particular que ele se aventura a fazê-lo, recusando a ingenuidade e o idealismo da fenomenologia, que afirma a possibilidade de apreensão do social, a partir das ações individuais dotadas de sentido, reduzindo, assim, a compreensão do social aos processos interativos entre indivíduos.

A postura de Bourdieu se afirma, por um lado, como negaçào de uma visão estruturalista objetivista, que desconsidera a ação dos agentes, e, por outro lado, como superação de uma compreensão ingênua da interação, que vê o mundo como intersubjetividade, sem percebê-lo de forma socialmente estruturada, permeada, nesse sentido, por relações de poder. Para além desses dois modelos de conhecimento, a postulação de Bourdieu é a da necessidade da elaboração de um conhecimento praxiológico, que tem como objeto não somente o sistema das relações objetivas, mas as relações dialéticas entre essas estruturas e as disposições estruturadas, nas quais elas se atualizam.

Importante registrar que Bourdieu não se detém numa "teoria teórica", como ele mesmo designa, que tem em si mesma o seu próprio fim, que surge e se desenvolve à base do confronto com outras teorias. É explícita a sua preocupação em escapar das "críticas

\footnotetext{
${ }^{2}$ Idem, Coisas ditas, Brasiliense, São Paulo, 1990, p. 21.
}

Temáticas, Campinas, 1(1/2):189-227, jul./dez. 1993. 
globalizantes", sem maiores preocupações empíricas, a exemplo dos trabalhos da Escola de Frankfurt, por ele criticados. Para Bourdieu, a teoria científica só é capaz de atingir o seu pleno significado a partir do confronto com a análise empírica e, nessa perspectiva, tem mais a ganhar com a defrontação com novos objetos do que com as polêmicas teóricas.

É a partir desse enfoque que podemos compreender melhor a variedade de questões que ele se propõe a analisar, a amplitude das temáticas que incorpora e o rigor conceitual que prima em manter, respeitando o compromisso com a elaboração de conceitos operacionais, capazes de dar conta das nuances e complexidades, envolvidas na produção sociológica. Talvez esteja aí uma das suas importantes contribuições à teoria social.

As alegativas para marcar a relevância de Bourdieu para a produção sociológica são as mais variadas. São destacados como elementos importantes: o caráter atípico do seu trabalho, visto como responsável pela repercussão e permanência da sua obra; a preocupação em considerar temas antes tidos como irrelevantes; o esforço significativo de pensar a prática como algo distinto da pura execução; além do fato de ter renovado e expandido a sociologia dos sistemas simbólicos. Sobre esse último ponto, gostaríamos de registrar que um dos seus maiores méritos é ter revelado o quanto há de político na cultura, que toda cultura é marcada por relações de poder.

A obra de Bourdieu, como qualquer trabalho expressivo, tem sido também objeto de uma série de questionamentos. É ele próprio quem aponta o determinismo, o totalitarismo e o pessimismo entre as críticas mais comuns de seus opositores. Teremos oportunidade de avaliar em que medida elas são consistentes. Neste primeiro momento, nos detivemos em traçar um quadro das preocupações norteadoras do trabalho de Bourdieu. Até que ponto ele foi capaz de atingir os seus objetivos é uma discussão que pretendemos desenvolver ao longo do texto.

Temáticas, Campinas, 1(1/2):189-227, jul./dez. 1993. 


\section{A Sociologia dos Bens Simbólicos de Pierre Bourdieu}

A Sociologia dos bens simbólicos de Bourdieu, como enunciamos, está centralmente informada pela busca de articulação entre estruturas e práticas, retomando com nuances particulares, o debate com o objetivismo e o subjetivismo. Na verdade, ela se constitui como busca de expressão da dialética entre essas duas dimensões. É precisamente para pensar essa relação, não apenas do ponto de vista da construção teórica, mas da análise empírica, que Bourdieu desenvolve o conceito de habitus. Nesse sentido, é dele que nos ocuparemos, inicialmente.

Bourdieu retoma o conceito aristotélico de habitus e repensa-o, num esforço de escapar do estruturalismo sem sujeito e da filosofia da consciência, sem anular o agente como operador prático da construção de objetos. Bourdieu define o habitus como "sistemas de disposições duráveis, estruturas estruturadas, predispostas a funcionar como estruturas estruturantes, isto é, como principio gerador $e$ estruturador das práticas e das representações que podem ser objetivamente 'reguladas' $e$ 'regulares' sem ser o produto da obediência a regras, objetivamente adaptadas a seu fim sem supor a intenção consciente dos fins e o dominio expresso das operaçōes necessárias para atingi-los e coletivamente orquestradas, sem ser o produto da ação organizadora de um regente" ${ }^{3}$

O habitus, enquanto sistema de esquemas adquiridos, funciona, a nível prático, como princípio de classificação e organização, o que implica na compreensão do agente social, como operador prático da construção de objetos. O habitus é matriz de percepções e apreciações das práticas adquiridas. Através dos determinantes sociajs que o produziram, o habitus está estreitamente articulado a uma condição social, bem como à posição social em que foi construído.

3 "Esboço de uma teoria da prática" in ORTIZ, R. (org.), Pierre Bourdieu - Sociologia, Ática, São Paulo, 1983, p. 61.

Temáticas, Campinas, 1(1/2):189-227, jul./dez. 1993. 
Sendo produto articulado das histórias individual e coletiva, configurado como uma espécie de "lei imanente" depositada nos agentes, pela experiência socializadora da educação, o habitus faz com que os agentes, "de forma consciente ou não", sejam produtores de "sentido objetivo", na medida em que suas ações e obras resultam de um modus operandi não produzido por ele. É nesse sentido que Bourdieu afirma-o como "origem de um conhecimento, sem consciência, de uma intencionalidade sem intenção". ${ }^{4}$

Uma outra dimensão importante, que o conceito de habitus permite apreender é a existência de outros princípios geradores das práticas, que o cálculo racional, a existência de uma "lógica prática", uma espécie de "sentido do jogo", que é de tal forma incorporado aos agentes, que transforma-se numa espécie de segunda natureza. ${ }^{5}$

Nesse sentido, ele se configura como fundamento objetivo de condutas regulares, o que faz de certo modo possível a previsão das práticas, na medida em que o "habitus faz com que os agentes que o possuam, comportem-se de uma determinada maneira, em determinadas circunstâncias" ${ }^{6}$ Contudo, a regularidade das condutas geradas pelo habitus não permite a inferência de deduções, como no caso das leis, dado, exatamente, o seu caráter de "lógica prática", que se define nas múltiplas relações cotidianas com o mundo, guardando, portanto, uma relação com o "fluido" e o "vago", ou seja, uma dimensão de indeterminação.

Do nosso ponto de vista, essa é a contribuição possível de ser extraída desse conceito, a incorporação da experiência prática, na definição das estratégias dos agentes. Contudo, essa não é a preocupação fundamental de Bourdieu ao constituí-lo e, na perspectiva para o qual foi concebido, ele nos parece claramente insuficiente, senão comprometedor.

${ }^{4}$ Coisas ditas, p. 5 , grifos nossos.

${ }^{5}$ Idem, ibidem, p. 82.

${ }^{6}$ Idem, ibidem, p. 98.

Temáticas, Campinas, 1(1/2):189-227, jul./dez. 1993. 
O habitus, tal como definido por Bourdieu, se assemelha a uma grande teia que, articulando posições e condições sociais, na forma de disposições, amarra os agentes em torno de opçōes bastante limitadas de movimento. Nessa perspectiva, os agentes teriam que se haver com opções dadas, mais do que constituí-las.

A concepção dos agentes, como suporte de habitus, constitui-se, assim, numa flexibilização, mas não numa superação da concepção dos agentes como suportes de estruturas. 0 papel do agente é visto de um ponto de vista passivo, cuja dimensão de criticidade, de reflexibilidade, desaparece. São as disposições estruturadas, dispostas a atuar como estruturas estruturantes, que moldam a ação dos agentes sociais, que, deste ponto de vista, apenas absorvem habitus, mas não o problematizam. Essa concepção limitada da capacidade de ação dos agentes, dá um certo caráter enrigecido à obra de Bourdieu.

Tendo anunciado algumas indicações acerca da ação dos agentes na sociedade, podemos agora analisar a própria concepção de sociedade que Bourdieu opera. Já adiantamos algumas considerações que permitem estabelecer um certo enfoque analítico, que explicitamente define o que ela não é. Ela não se dissolve no mundo compreensivo dos agentes, nem tampouco se esgota nas estruturas objetivas que a compõem. Na nossa compreensão, há pelo menos três elementos qualificadores da sociedade para Bourdieu: ela é compreendida como um grande mercado de bens materiais e simbólicos, que diferenciase em diversos campos e que é estruturalmente marcada por um processo de estratificação social.

Cada um destes três pontos será objeto de reflexão a seguir, enfocado sob a ótica da possível contribuição de Bourdieu para a sociologia dos bens simbólicos, ou como prefere Micelli, dos "sistemas simbólicos". ${ }^{7}$ Estas noções estão profundamente imbricadas e é possível que façamos referências comuns, na análise de cada um destes pontos.

${ }^{7}$ MICELLI, Sérgio, "A força do sentido", in A Economia das trocas simbólicas, 2a. edição, Perspectiva, São Paulo, 1987, p. X.

Temáticas, Campinas, 1(1/2):189-227, jul./dez. 1993. 
A compreensão da sociedade como um mercado não constitui uma contribuição original de Bourdieu à Sociologia. 0 fato de que as diferentes sociedades desenvolveram-se recorrendo ao mecanismo do mercado, para suprirem as suas necessidades materiais, é linguagem corrente. A novidade é a referência a um mercado de bens simbólicos tão vigoroso quanto o de bens materiais. Ao estabelecerem relações sociais entre si, os homens não somente trocam mercadorias, mas também significados, símbolos. ${ }^{8}$

Há, assim, uma lógica da produção, circulação e consumo dos bens simbólicos, a ser apreendida e analisada. É um pouco o que faz Bourdieu ao afirmar a "autonomia relativa" deste mercado simbólico, que, não obstante, é analisado a partir da mesma ótica do mercado de bens materiais, configurado pela existência de: produtores e consumidores de bens simbólicos, que movimentam-se no âmbito de um mercado, a partir de um certo quantum de capital, que os capacita ou não a fazer frente aos preços estipulados num processo de competição.

Bourdieu, ao discutir a questão do mercado, não o faz de uma maneira genérica e indiferenciada. Ele especifica a noção de mercado através da compreensão do significado e funcionamento do campo. $\mathrm{Na}$ sua concepção aos vários campos correspondem mercados específicos, sendo a lógica de funcionamento de cada mercado, definida pelo campo que o delimita. Nesse sentido, o entendimento da visão de Bourdieu sobre o mercado de bens simbólicos só se faz possível, na sua íntima relação com o processo de configuração de um campo cultural.

Para Bourdieu, é fundamental o reconhecimento e a análise do processo de autonomização do sistema de relações de produção, circulação e consumo de bens simbólicos, que liberou-se, de forma progressiva, das instâncias de legitimação externas, como a Igreja e a Aristocracia na Idade Média, tornando possível a construçāo de

${ }^{8}$ BOURDIEU, Pierre, "O mercado de bens simbólicos" in A economia das trocas simbólicas, pp. 102-103.

Temáticas, Campinas, 1(1/2):189-227, jul./dez. 1993. 
legitimidades culturais, definidas a nível interno do próprio campo.

Este processo de autonomização desenvolveu-se conjuntamente a uma série de transformações sumamente importantes como: a constituição de um público de consumidores virtuais, extenso e diversificado, que conferiu aos produtores de bens culturais, condições mínimas de independência econômica e um princípio de legitimidade; a constituição de um corpo amplo e diferenciado de produtores e empresários de bens simbólicos; além da multiplicação e diversificação das instâncias de consagração, que passaram a competir pela legitimidade cultural. ${ }^{9}$

A liberdade de artistas e produtores culturais, pleiteada e, num certo sentido, desenvolvida historicamente com a ruptura dos laços de dependência com monarcas e com a Igreja, de um outro ponto de vista, mostrou-se progressivamente como tendo um caráter formal, condicionando artistas e produtores a um novo tipo de submissão às leis do mercado de bens simbólicos.

Esta questão será melhor desenvolvida, quando discutirmos a noção de campo, a seguir. É a "teoria geral da economia dos campos", que permite definir a forma específica que assume em cada campo os mecanismos e os conceitos gerais, tais como capital, investimento, ganho, fugindo assim das posturas reducionistas que limitam essas relações ao interesse material e a maximização do interesse monetário ${ }^{10}$

Bourdieu concebe o ordenamento da sociedade a partir da sua teoria dos campos, evitando a sua configuração, nos moldes marxistas clássicos, que a compreende a partir do binômio estrutura e superestrutura ${ }^{11}$ Busca, nesse sentido, estabelecer um viés de análise mais amplo, que dê conta da multiplicidade de determinações que configuram as relações sociais e as especificam. A idéia da autonomia dos campos constitui um esforço nesse sentido. Analisando

\footnotetext{
${ }^{9}$ Idem, ibidem, p. 100.

${ }^{10}$ Idem, $O$ poder simbólico, p. 69.

${ }^{11}$ CANCLINI, Néstor, Desigualdad cultural y poder simbólico, p. 12.
}

Temáticas, Campinas, 1(1/2):189-227, jul./dez. 1993. 
a sua obra, Canclini reconhece a mudança de perspectiva, que envolve a utilização da noção de campo. "Nas sociedades 'modernas', a vida social se reproduz em campos (económico, político, científico), que funcionam com uma forte independência. As lutas que em cada campo ocorrem não podem ser dedutiveis do caráter geral da luta de classes, mas do entendimento do próprio campo". ${ }^{12}$

O campo, para Bourdieu, é concebido como estruturado a partir de dois elementos: um capital específico comum, que dá sentido à sua existência e um processo permanente de luta pela apropriação desse capital. "Para que um campo funcione, é preciso que haja objetos de disputa e pessoas prontas para disputar o jogo, dotadas de habitus que impliquem no conhecimento e no reconhecimento das leis imanentes do jogo, dos objetos de disputa, etc. ${ }^{13}$

É exatamente essa luta que movimenta e sustenta a existência do campo que, sendo produzida pelas próprias estruturas constitutivas do campo, produz, por outro lado, suas estruturas e hierarquias. ${ }^{14}$ $\mathrm{O}$ campo funciona à medida em que o conjunto dos seus agentes atua para manter ou melhorar suas posições, no interior do campo, uma luta que terá maiores chances de êxito a partir da posse de um maior domínio do capital específico do campo.

Para Bourdieu, compreender a atuação dos agentes, implica romper com uma visão da dominação, como tendo um caráter centralizado e único, que é incapaz de aprender a contribuição particular dos vários agentes que, não só na condição de dominantes, mas também como dominados, contribuem para a manutenção do exercício da dominação, na medida em que aceitam as regras do jogo e participam dele. "A submissão a certos fins, significaçõos ou interesses transcendentes, quer dizer, superiores e exteriores aos interesses individuais, raramente é feito de uma imposição imperativa e de uma

\footnotetext{
${ }^{12}$ Idem, ibidem, p. 12.

${ }^{13}$ BOURDIEU, Pierre, Questóes de sociologia, Marco Zero, Rio de Janeiro, 1983, p. 89.

${ }^{14}$ Idem, $O$ poder simbólico, p. 85.
}

Temáticas, Campinas, 1(1/2):189-227, jul./dez. 1993. 
submissäo consciente ${ }^{15}$ Nesse sentido é que se pode compreender a afirmativa acerca de uma cumplicidade básica subjacente a todas as lutas, no interior dos diversos campos, que advém da crença, no valor do próprio jogo, no qual se deparam desigualmente os diversos participantes.

Contudo, no mesmo instante em que Bourdieu reconhece o significado da atuação dos agentes, ele desqualifica essa intervenção, definindo-a como uma contribuição que "os agentes (inclusive os dominados) dão, quer queiram, quer não, quer saibam que não, para o exercício da dominação por meio da relação que se estabelece entre as suas atitudes, ligadas às suas condições sociais de produção, e as expectativas $e$ interesses inscritos nas suas posições no seio desses campos de luta". ${ }^{16}$ Os agentes, nesse sentido, são destituídos da sua capacidade reflexiva e criadora, apenas "movimentando-se" de acordo com as suas condições sociais e atendendo as expectativas das suas posições no campo.

O campo, para Bourdieu, está estruturado de maneira bipolar, a partir da oposição entre dominantes e dominados. Às diferentes posições e aos capitais específicos respectivos correspondem diferentes estratégias de luta. Os dominantes, na condição de detentores de um elevado capital específico, primam pela "ortodoxia", na tentativa de conservar o capital acumulado, enquanto os dominados, desprovidos de tal capital acumulado ou possuindo-o, em níveis menores, desenvolvem o que Bourdieu designa como "práticas heterodoxas", visando promover o descrédito dos detentores de capital. "O campo se particulariza, pois, como um espaço onde se manifestam relaçóes de poder, o que implica afirmar que ele se estrutura a partir da distribuição desigual de um quantum social que determina a posição que um agente especifico ocupa em seu seio". ${ }^{17}$

\footnotetext{
${ }^{15}$ Idem, ibidem, p. 87.

${ }^{16}$ Idem, ibidem, p. 87, grifos nossos.

${ }^{17}$ ORTIZ, Renato, "A procura de uma sociologia na prática", in Bourdieu, Sociologia, Ática, São Paulo, p. 21.
}

Temáticas, Campinas, 1(1/2):189-227, jul./dez. 1993. 
A compreensão do funcionamento do campo, contudo, não se limita ao entendimento do próprio campo, mas deve recuperar as posições dos.agentes ao nível interno e externo do campo, ao nível da sociedade global, ou seja, deve ser referido à estratificação da sociedade. Vejamos como Bourdieu discute o funcionamento do campo cultural, que nos interessa particularmente, para a seguir nos determos na questão da estratificação.

Bourdieu compreende o campo de produção e circulação dos bens simbólicos como "campo das relações de concorrência pelo monopólio do exercício legítimo da violência simbólica" ${ }^{18}$ estando ele ordenado em torno de duas oposições. Uma primeira relação, de oposição e complementariedade, ocorre entre o campo de produção erudita e o campo das instâncias de conservação e consagração de capital simbólico, a quem cabe salvaguardar uma ortodoxia cultural, defendendo a "cultura legítima", diante de manifestações culturais concorrentes ou heréticas, assegurando a conservação e a transmissão seletiva dos bens simbólicos.

Uma segunda relação de oposição se verifica entre o campo de produção erudita e o campo da indústria cultural. O primeiro, sendo dirigido a um público de produtores de bens culturais, estabelece suas próprias normas de validação, que se constituem também em princípios distintivos do seu público específico. O segundo, organizado com vistas à produção de bens culturais para um "público médio", pauta-se pela lei da concorrência, ou seja, do mercado. Nesse sentido, configura-se como resultado da conjunção entre o interesse numa produção lucrativa, orientada para o crescimento e a dispersão da composição sócio-cultural do público, e as transações e compromissos estabelecidos entre os agentes do campo.

$\mathrm{Na}$ medida em que "todo ato de produção cultural implica na afirmação de sua pretensão à legitimidade cultural ${ }^{19}{ }^{19}$ ou seja, à luta pelo monopólio da manipulação legítima de uma determinada

\footnotetext{
${ }^{18}$ BOURDIEU, Pierre, "O mercado de bens simbólicos", p. 118.

${ }^{19}$ Idem, ibidem, p. 108.
}

Temáticas, Campinas, 1(1/2):189-227, jul./dez. 1993. 
espécie de bens simbólicos, fica estabelecido o conflito, tendo por base a existência de princípios diferenciados de legitimação.

Há, na sociologia dos campos de Bourdieu, uma nítida centralidade da noção de posição, como princípio explicativo das práticas e das obras dos agentes. Os campos, de um ponto de vista sincrônico, constituem "espaços estruturados de posições". ${ }^{20}$ A estrutura do campo configura-se como expressão de um "estado" das relações de força, entre os agentes ou as instituições em luta pelo monopólio da "violência simbólica legítima". Para Bourdieu, “a cada uma das posições no campo de produção e circulação corresponde, a título de potencialidade objetiva, um tipo particular de posições culturais (ou seja, um lote particular de problemas e esquemas de soluçâo, temas e procedimentos, posições estéticas e políticas, etc.)". ${ }^{21}$

Nessa perspectiva é que Bourdieu aponta a insuficiência de uma análise de caráter interno da estrutura de relações simbólicas, só compreensível mediante uma análise sociológica da estrutura do sistema de relações sociais de produção, circulação e consumo simbólicos, no qual foram engendrados e assumiram funções sociais específicas.

Além de uma preocupação de caráter metodológico expresso nessa formulação, o que fica evidenciado é a centralidade das relações de poder na Sociologia de Bourdieu, que privilegia, em todas as relações sociais humanas, essa dimensão constitutiva fundamental. “Os estudos de Bourdieu acentuam, sobretudo, essa dimensão social em que as relações entre os homens se constituem em de poder, mais ainda, em que elas reproduzem o sistema objetivo de dominação interiorizado enquanto subjetividade; a sociedade é dessa forma apreendida como estratificação de poder. $" 22$

Segundo Canclini, ao explicar a estrutura de todos os campos, segundo a lógica interna da luta pelo poder, ele deixa de tratar dois

${ }^{20}$ Idem, Questões de sociologia, p. 89.

${ }^{21}$ Idem, "O mercado de bens simbólicos", p. 159.

${ }^{22}$ ORTIZ, Renato, “A procura de uma sociologia da prática”, pp. 25-26.

Temáticas, Campinas, 1(1/2):189-227, jul./dez. 1993. 
problemas importantes: o que acontece especificamente em cada campo e como se dá a relação entre os campos e a história. ${ }^{23} \mathrm{~A}$ configuração dos campos, a partir de uma estrutura bipolar, que reduz o conjunto das relações sociais ao conflito entre dominantes e dominados, constitui uma simplificação, que subsume manifestações de diferenças e pluralidades sob o rótulo de relações de poder.

Se é verdade que o conjunto das relaçōes sociais é permeado por relações de poder, também é notório que essa não é a sua única dimensão, bem como nem sempre assume o caráter de maior importância. Deste ponto de vista, Bourdieu empobrece e limita a análise, na medida em que a desenvolve precipuamente sob a ótica do político e constrói um modelo que, pautado nesse ênfase, desqualifica outras dimensões constitutivas das práticas.

Para Bourdieu, a compreensão da sociedade como tendo um caráter estratificado, implica finalmente na necessidade da análise da questão das classes de um ponto de vista relacional. "Com base no conhecimento do espaço das posições, podemos recortar classes no sentido lógico do termo, quer dizer, conjuntos de agentes que ocupam posições semelhantes e sujeitos a condicionamentos semelhantes, têm, com toda a probabilidade, atitudes e interesses semelhantes, logo, práticas e tomadas de posições semelhantes. ${ }^{24}$ As classes, na medida em que ocupam uma posição numa estrutura social historicamente definida, e que mantêm relações com outras partes constitutivas da estrutura possuem "propriedades de posição" que são relativamente independentes de propriedades intrínsecas, como por exemplo advindas de um certo tipo de condições materiais de existência.

Bourdieu postula a existência de propriedades de situação e de posição, só dissociáveis por uma "operação do espírito", que devem ser recuperadas, de modo conjunto e articulado, na análise da estratificação social. As relações sociais são explicáveis, mediante a

${ }^{23}$ CANCLINI, Néstor, op. cit., p. 15.

${ }^{24}$ Bourdieu, Pierre, $O$ poder simbólico, p. 136.

Temáticas, Campinas, 1(1/2):189-227, jul./dez. 1993. 
articulação das relações entre condições e posições sociais, sendo as primeiras definidoras da "margem restrita de variação", conferida às segundas. ${ }^{25}$

Num dos trabalhos mais maduros de Bourdieu, $O$ poder simbólico, a questão da construção de uma "teoria do espaço social" é desenvolvida a partir da demarcação de algumas rupturas com o marxismo, de certo modo, já antecipadas em outros trabalhos, sendo explícita a sua preocupação em estabelecer limites e diferenças do seu pensamento com essa tradição, com a qual tem significativas afinidades, mesmo que nem sempre reconhecidas.

São identificadas, por Bourdieu, três rupturas fundamentais a serem feitas com o marxismo. Primeiramente com a tendência marxista de privilegiar as substâncias (os grupos reais) em detrimento das relações, a partir de uma visão "intelectualista" que confere à classe um sentido real efetivo, desconsiderando o seu caráter de conceito construído. "É preciso afirmar, contra o realismo do inteligivel (ou reificação dos conceitos), que as classes que podemos recortar no espaço social (por exemplo, por exigências da análise estatística que é o único meio de revelar a estrutura do espaço social) não existem como grupos reais embora expliquem a probabilidade de se constituírem em grupos práticos, familias (homogamias), clubes, associações e mesmo 'movimentos' sindicais ou políticos. "26

Bourdieu rejeita, portanto, tanto o "relativismo nominalista", quanto o "realismo do inteligível". No primeiro caso, contra a visão que reduz as diferenças sociais a meros artefatos teóricos, afirma a existência de um espaço objetivo, definidor de compatibilidades e incompatibilidades, proximidades e distâncias. No segundo caso, nega uma visão reificadora dos conceitos, mediante a postulação de que as classes, que podemos recortar no espaço social, não existem como grupos reais, embora estejam potencialmente em condições de se constituírem em grupos de caráter diverso.

\footnotetext{
${ }^{25}$ Idem, "Condição de classe e posição de classe", p. 04.

${ }^{26}$ Idem, $O$ poder simbólico, p. 136.
} 
Uma segunda ruptura, afirmada como fundamental, deveria ser feita com o economicismo que, ao reduzir o conjunto das relações sociais ao campo econômico, como categoria fundamental explicativa, deixa de perceber o campo social como "espaço multidimensional" de posições. "Pode-se descrever o campo social como um espaço multidimencional de posiçōes tal que qualquer posição actual pode ser definida em função de um sistema multidimensional de coordenadas cujos valores correspondem aos valores das diferentes variáveis pertinentes: os agentes distribuem-se assim nele, na primeira dimensão, segundo o volume global do capital que possuem $e$, na segunda dimensão, segundo a composição do seu capital - quer dizer, segundo o peso relativo das diferentes espécies no conjunto das suas posses. ${ }^{~ 27} \mathrm{Tal}$ afirmativa traz uma contribuição importante à teoria social, embora nem sempre seja considerada efetivamente pelo próprio Bourdieu.

Uma última ruptura deveria ser feita com o objetivismo, que minimiza a importância da dimensão simbólica, do "trabalho de representação", para a compreensão das relações sociais. Bourdieu sustenta que o entendimento do mundo social implica num ato de construção também. A representação que os agentes têm do mundo social contribui para a construção da visão desse mundo e, nesse sentido, para a sua própria construção, o que se faz, evidentemente, através de uma série de lutas, que envolve a definição legítima de conceitos, estabelecendo princípios de "visão" e "divisão". "O poder de impor uma visão das divisões, isto é, o poder de tornar visiveis, explícitas, as divisões sociais implícitas, é o poder político por excelência: é o poder de fazer grupos, de manipular a estrutura objetiva da sociedade. ${ }^{228}$

É exemplar que uma das suas obras mais maduras receba o título de $O$ poder simbólico, dado o relevo que Bourdieu sempre conferiu a essa questão do poder, sob cuja ótica o simbólico é visto. Para ele,

\footnotetext{
${ }^{27}$ Idem, ibidem, p. 167.

${ }^{28}$ Idem, ibidem, p. 167.
}

Temáticas, Campinas, 1(1/2):189-227, jul./dez. 1993. 
“o poder simbólico é, com efeito, esse poder invisível o qual só pode ser exercido com a cumplicidade daqueles que não querem saber que lhe estão sendo sujeitos ou mesmo que o exercem". ${ }^{29}$

Bourdieu identifica duas tradições básicas, no entendimento dos "sistemas simbólicos". Uma primeira que o compreende como "estruturas estruturantes" e uma segunda como "estruturas estruturadas". Na primeira variante, os diferentes universos simbólicos, mitos, língua, arte, ciência são ao mesmo tempo instrumentos de conhecimento e de construção do mundo. Na segunda vertente é realçada a dimensão estrutural desses sistemas, privilegiando-se o opus operatum sobre o modus operandi.

É importante compreender que é enquanto instrumentos estruturados e estruturantes de comunicação e de conhecimento que os sistemas simbólicos exercem a função política de imposição e legitimação da dominação, assegurando, mediante a "violência simbólica" o domínio de classes. Nesse sentido, o campo de produção simbólica se configura como um "microcosmo da luta simbólica de classes" 30 e é na medida em que servem aos seus interesses, ao nível da luta interna do campo, que os produtores servem aos interesses dos grupos, que são exteriores ao campo de produção. Nesse sentido é que se pode afirmar que o poder simbólico é um "poder subordinado, é uma forma transformada, quer dizer, irreconhecivel, transfigurada $e$ legitimada, das outras formas de poder" ${ }^{31}$

O sistema simbólico, para Bourdieu se estrutura a partir da "lógica da diferença", que constitui distinções significantes, no espaço social. Todo consumo e de forma geral, toda a prática, tendo ou não sido realizado para ser visto, notado, percebido, ele é distintivo. Configura-se como "sinal distintivo", podendo assumir a condição de "sinal de distinção", nos casos em que se constitui como diferença reconhecida como legítima. Os agentes sociais, além de

\footnotetext{
${ }^{29}$ Idem, ibidem, p. 08.

${ }^{30}$ Idem, ibidem, p. 12

${ }^{31}$ Idem, ibidem, p. 15.
}

Temáticas, Campinas, 1(1/2):189-227, jul./dez. 1993. 
reconhecerem como "distinçōes significantes" as diferenças, podem buscar aumentar intencionalmente tais diferenças "espontâneas" de estilos de vida. "A procura da distinção - que pode marcar-se nas maneiras de falar ou na recusa a um casamento desigual - produz separações destinadas a serem percebidas ou, melhor, conhecidas $e$ reconhecidas como diferenças legitimas, quer dizer, na maior parte dos casos, como diferenças de natureza. ${ }^{\# 2}$

Creio, pelo conjunto das questões apresentadas ao longo do texto, já estarmos em condições de formular a crítica mais fundamental ao trabalho de Bourdieu e que atinge de maneira frontal seus propósitos analíticos. Referimos-nos à perspectiva marcadamente objetivista que assume o conjunto da sua obra e que, neste sentido, evidencia o fracasso da sua tentativa de articular de maneira efetiva o objetivismo e o subjetivismo, através do conhecimento praxiológico. Destacaremos, a fim de corroborar essa afirmativa, duas ordens de questões. A primeira, referente à compreensão do agente, postulada por Bourdieu e a segunda, que diz respeito ao seu entendimento da esfera simbólica e seu significado específico.

Sem nenhuma dúvida, há em Bourdieu um questionamento contundente às visões objetivistas, especialmente, nas versões estruturalistas, que ignoram a ação dos agentes, compreendendo-os como trager de estruturas, executores de modelos que lhes são exteriores. "Eis a raiz do ponto mais consistente e original da contribuição de Bourdieu, qual seja o esforço de pensar a prática como algo diverso do produto 'pobre' e 'menor', de um modelo abrangente ao qual a ciência objetivista confere mais realidade do que à própria realidade. ${ }^{33}$

Não obstante o seu esforço, a tentativa de Bourdieu é comprometida seriamente nas suas análises. Os agentes deixam de se configurar como suportes de estruturas, para se transformarem em suporte de habitus, "prisioneiros" do habitus, compreendido como um

${ }^{32}$ Idem, ibidem, p. 144.

${ }^{33}$ MICELLI, Sérgio, op. cit., p. XXVIII.

Temáticas, Campinas, 1(1/2):189-227, jul./dez. 1993. 
sistema de disposições estruturadas, nas quais as estruturas se atualizam e que se configura como produto da incorporação da "necessidade objetiva", espécie de lei imanente depositada nos agentes pela experiência inicial da educação.

$\mathrm{Na}$ preocupação de escapar do interacionismo simbólico e da etnometodologia, que reduz as relações sociais e encontros de indivíduos, num processo interativo, Bourdieu termina por cair no extremo oposto, conferindo um "sentido objetivo" às práticas dos agentes, que transcenderia às intenções subjetivas e aos projetos conscientes individuais e coletivos.

Essa questão é bastante visível, numa afirmação de Bourdieu: "as relações sociais não são jamais redutiveis a relações entre subjetividades movidas pela busca de prestigio ou por qualquer outra 'motivação' porque elas não passam de relações entre condições $e$ posições sociais que se realizam segundo uma lógica propensa a exprimi-las $e$, por este motivo, estas relações sociais têm mais realidade do que os sujeitos que as praticam". ${ }^{34}$ Na verdade, embora manifestamente preocupado em recuperar a dialética da interiorização da exterioridade e da exteriorização da interioridade, Bourdieu privilegia a primeira dimensão, fixando-se numa postura objetivista.

Na nossa visão, é essa concepção que compromete o projeto teórico de Bourdieu, configurando-o nos termos de uma "sociologia da reprodução". Na medida em que o habitus é a expressão em forma de disposições, das estruturas, e que a ação dos agentes é ordenada pelo habitus, a margem deixada à uma ação criativa transformadora é mínima.

Canclini e Ortiz, nas suas análises sobre a obra de Bourdieu, partilham a mesma compreensão de que sua teoria social assume uma feição reprodutivista, que dificulta a compreensão dos processos de mudanças e, nesse sentido, da própria incorporação da dimensão da história, no seu pensamento. "Dito de outra maneira, se o habitus

${ }^{34}$ BOURDIEU, Pierre, "Condição de classe e posição de classe", p. 25, grifos nossos.

Temáticas, Campinas, 1(1/2):189-227, jul./dez. 1993. 
se define por sua tendência à reprodução, como articulá-lo ao movimento da mudança social? O habitus, mediação entre o agente social e a sociedade, se exprime desta forma, necessariamente no interior de um ciclo de reprodução, a análise se encerrando num círculo vicioso, o que implica renunciar-se à problemática da História. ${ }^{\$ 35}$

Isto posto, retomemos o segundo ponto, referente à compreensão de Bourdieu acerca da esfera simbólica. Como já tivemos a oportunidade de apresentar, há toda uma formulação acerca da questão da autonomia dessa esfera e uma severa crítica às formulações que, sem compreender a sua especificidade, atribuem-na uma condição de reflexo da esfera econômica, como é o caso do marxismo clássico. A esfera simbólica ganha, em Bourdieu, um estatuto diferenciado, sendo amplamente discutida e contribuindo para dar maior legitimidade à sociologia dos sistemas simbólicos.

Para Canclini, seguindo a linha de Weber e Gramsci, Bourdieu persegue uma explicação simultaneamente econômica e simbólica dos processos sociais. ${ }^{36}$ De fato, essa articulação nem sempre é feita de um ponto de vista inovador, reaparecendo sob novas roupagens a visão reprodutivista, anteriormente mencionada. Nessa perspectiva, consideramos profundamente revelador o aparelho categorial tomado por Bourdieu para analisar os sistemas simbólicos, numa transposição pouco rigorosa de conceitos, concebidos para pensar as relações econômicas, para refletir os domínios da construção dos significados.

É vigorosa a preocupação de Bourdieu com as categorias classificatórias, na sua capacidade de comprometimento dos próprios conteúdos analíticos. Gostaríamos de insitir que não é desavisadamente, portanto, que utiliza categorias como capital simbólico, mercado cultural, etc. Se as classificações classificam os classificadores,${ }^{37}$ como afirma Bourdieu, tais conceitos evidenciam

\footnotetext{
${ }^{35}$ ORTIZ, Renato, op. cit., p. 26.

${ }^{36}$ CANCLINI, Néstor, op. cit., p. 35.

${ }^{37}$ BOURDIEU, Pierre, Coisas ditas, p. 159.
}

Temáticas, Campinas, 1(1/2):189-227, jul./dez. 1993. 
explicitamente o comprometimento da sua proposta de pensar uma esfera simbólica, com algum grau de autonomia.

Nessa perspectiva é revelador, em Bourdieu, o reconhecimento de uma "autonomia relativa das relações simbólicas", desenvolvida dentro de uma "margem restrita de variação", deixada pelas condições de existência ${ }^{38}$ e as referências não ocasionais a um certo caráter "duplicador" dos simbolos, vistos como a materialização de um sistema particular de estruturas objetivas. ${ }^{39}$ Esta é uma questão recorrente nas suas análises da questão da distinção: "as distinções simbólicas são sempre secundárias em relação às diferenças econômicas, que as primeiras exprimem, transfigurando-as ${ }^{40}$

Para Bourdieu, as ações simbólicas exprimem sempre a posição social, a partir da lógica da distinção. As marcas da distinção são vistas como duplicação simbólica dos valores de posição vinculados a cada posição na estrutura social. ${ }^{41}$ Sendo, para Bourdieu, a lógica da distinção a forma por excelência do jogo propriamente cultural, a sua análise da cultura está centralmente informada por essa perspectiva.

\section{O MERCAdo Lingüístico}

A discussão de Bourdieu sobre o mercado lingüístico configurase como uma expressão da sua tentativa de articular os modos de conhecimento objetivista e fenomenológico, através do conhecimento praxiológico, que tem como objetivo não apenas o sistema de relações objetivas, mas as relações "dialéticas" entre essas estruturas e as disposições estruturadas, nas quais elas se atualizam. ${ }^{42}$

${ }^{38}$ Idem, Condição de classe e posição de classe, p. 25, grifos nossos.

${ }^{39}$ Idem, ibidem, p. 14.

${ }^{40}$ Idem, ibidem, p. 15.

${ }^{41}$ Idem, ibidem, p. 14.

${ }^{42}$ Idem, "Esboço de uma teoria da prática", p. 47.

Temáticas, Campinas, 1(1/2):189-227, jul./dez. 1993. 
Tomado como expressão do objetivismo no campo da linguagem, Saussure é eleito por Bourdieu como interlocultor privilegiado. A lingüística saussureana privilegia a estrutura dos signos sobre as suas funções práticas de comunicação e conhecimento, bem como políticas e econômicas, concebendo a língua como objeto autônomo, irredutível às suas manifestaçōes concretas.

A compreensão da língua como código legislativo e comunicativo, existente de forma exterior aos seus utilizadores (os sujeitos falantes) e às suas utilizações ("fala"), reduz as ações no mercado lingüístico a um ato de comunicação, que precisa ser decifrado. Para Bourdieu, a Sociologia deveria incorporar as contribuições da Lingǘstica, assumindo, contudo, um ponto de vista crítico, substituindo a noção de gramaticalidade pela de aceitabilidade, as relações de comunicação pelas relações de força simbólica e a questão do sentido do discurso pela do valor e poder do discurso, o que implica a compreensão não apenas de uma competência lingüística, mas de um capital simbólico.

Falar em capital lingüístico significa recusar a abstração contida no conceito de competência lingüística, como capacidade infinita de engendramento de discursos, que postula a autonomização da capacidade de produção lingüística. Para Bourdieu, a linguagem é uma práxis, necessariamente referida às situaçōes que lhe conferem um sentido e condicionam a sua expressão. A linguagem, feita para ser falada, se por um lado deve assumir os pressupostos gramaticalmente definidos como legítimos, deve, por outro lado, ser falada adequadamente, ou seja, considerando as condições em que é utilizada.

A competência chomskyana configura-se como abstração, para Bourdieu, porque ignora o domínio prático das situações, que indica quando é preciso falar, calar, o que é preciso dizer, calar, etc., reduzindo a competência comunicativa ao domínio da linguagem, como capacidade de engendramento infinito de discurso gramatical correto.

Temáticas, Campinas, 1(1/2):189-227, jul./dez. 1993. 
Para Bourdieu, trata-se de eleger, como elemento central da análise da linguagem, as condiçōes sociais de possibilidade da produção e circulação lingüísticas. Os discursos só se fazem compreensíveis na estreita relação que mantêm com as relações de produção lingüísticas em que ele é produzido. Daí a crítica de Bourdieu a uma estratégia de análise fundada na busca das formas invariantes de percepção, na medida em que os signos só adquirem uma existência efetiva, a partir das situações concretas que as atualizam.

A análise da questão da linguagem deve, portanto, ter em conta que a construção das percepções não se dá num vazio social, mas está submetida a coações estruturais, ou seja, que as estruturas estruturantes também são socialmente estruturadas. Um último aspecto a ser considerado, e que marca a separação de Bourdieu com as correntes subjetivistas, refere-se ao caráter coletivo da construção das percepções sociais, que implica numa ruptura com as visões microsociológicas da fenomenologia.

Este é um ponto importantíssimo na formulação de Bourdieu que, para além das aproximações com a fenomenologia, na postura crítica ao objetivismo, expresso na sua versão da lingüística estruturalista, marca a existência de diferenciaçōes significativas. Há uma identidade inegável em ambas as formulações, que é a da busca da recuperação da dimensão subjetiva da construção do significado, o reconhecimento do papel ativo dos agentes na sua apreensão do mundo, ou seja, a crítica quanto ao caráter de "meros executores", conferido pelo estruturalismo aos agentes.

A fenomenologia compreende o mundo objetivo como uma "rede de intersubjetividade", configurada como resultado das açōes referidas sempre a um "outro", questionando o argumento que toma o agente da comunicação como "impessoal" e "intercambiável". Tais ações só adquirem significado na medida em que falante e ouvinte compartilham um mesmo mundo social. A ação social deixa de configurar-se como mera execução, constituindo-se também como produtora de significados. A abordagem fenomenológica,

Temáticas, Campinas, 1(1/2):189-227, jul./dez. 1993. 
contudo, ao reintroduzir o agente social desconsiderado pelo objetivismo, negligência o caráter socialmente estruturado das interações, tornando-se também alvo das críticas de Bourdieu.

$\mathrm{Na}$ verdade, as interaçōes não são apenas relações comunicativas entre um "eu" e um "outro"; os agentes sociais, ao iniciarem qualquer relação de comunicação, o fazem a partir de um campo, no qual as posições sociais já estão objetivamente estruturadas. Nesse sentido, estabelecem também relações de poder, que reproduzem a desigualdade de poderes ao nível da sociedade global. Esta é a principal objeção de Bourdieu à corrente fenomenológica: a negligência às análises das relações de poder que permeia e constitui de fato as diversas formas de interação, o que implica negar a compreensão do mundo como intersubjetividade, uma concepção cara aos interacionistas simbólicos.

As "trocas simbólicas", como designa Bourdieu, são também relações de poder. Nesse sentido, a produção e a circulação lingüística só podem ser analisadas do ponto de vista da relação entre o habitus lingüístico e os mercados. Os atos de fala são uma conjunção de "séries causais". ${ }^{43}$ De um lado, as disposições do habitus lingüístico implicam numa propensão a dizer coisas gramaticalmente conforme em situaçōes específicas. De outro lado, as estruturas do mercado lingüístico, impõem sanções e censuras a ser consideradas pelos agentes.

O espaço da interação funciona como uma situação de mercado lingüístico pré-constituído, definidor do que pode ou não ser dito, de quem é excluído e quem se exclui. ${ }^{44} \mathrm{O}$ espaço da interação é também o espaço da atualização da interseç̧ão entre os diferentes campos. Os agentes, na luta pelas "definições" legítimas, dispõem de forças, que estão referenciadas aos campos hierarquizados e às posições que ocupam nos campos respectivos.

\footnotetext{
${ }^{43}$ Idem, Ce que parle veut dire, Librairie Artheme Fayard, p. 14. ${ }^{44}$ Idem, $O$ poder simbólico, p. 55.
}

Temáticas, Campinas, 1(1/2):189-227, jul./dez. 1993. 
Este é um elemento importante, as palavras são objeto de disputa, uma intensa luta pela nomeação legítima. $O$ poder de nomear é também, como afirma Bourdieu, o poder de fazer coisas, daí um certo caráter "mágico" estar presente na definição dos significados, na medida em que alterar representações implica, num certo sentido, em mudar as coisas. $O$ agente que fala não busca, apenas, ser compreendido, mas também ser obedecido, acreditado, reconhecido. " $A$ língua não é somente um instrumento de comunicação ou mesmo de conhecimento, mas um instrumento de poder. $" 45$

Nesse sentido, a fala dos agentes deve ser compreendida não só do ponto de vista de uma operação intelectual de "cifraçãodecifração", mas como uma "relação de força simbólica, que se baseia numa relação de autoridade-crença" ${ }^{46}$ necessariamente referida às condições de instauração dos discursos, mais precisamente, à estrutura do mercado em que é proferido. "A ciência do discurso deve levar em conta as condições de instauração da comunicação, porque as condições de recepção esperadas fazem parte das condições de produção. A produção é comandada pela estrutura do mercado ou, mais precisamente, pela competência (no sentido pleno) na sua relação com um mercado." 47

A autoridade de um discurso, ou seja, que confere a um discurso o caráter legítimo, capaz de se impor como tal, decorre de uma série de fatores, ressaltados por Bourdieu. Em primeiro lugar, ele é proferido por um locutor legítimo, reconhecido como tendo o direito e a competência de proferí-lo. Segundo, ele é proferido numa situação legítima, ou seja, no mercado que o considera relevante. Por último, ele é dirigido a destinatários também legítimos, ou seja, capazes de compreendê-lo e dar-lhe a importância devida.

O discurso constitui-se, pois, como um bem simbólico, que pode receber valores diferenciados, de acordo com o mercado, no qual

\footnotetext{
45 "A economia das trocas lingüisticas", in Bourdieu, p. 161.

${ }^{46}$ Idem, ibidem, p. 161.

${ }^{47}$ Idem, ibidem, pp. 161-162.
}

Temáticas, Campinas, 1(1/2):189-227, jul./dez. 1993. 
ele é proferido. $O$ que determina o discurso é a relação objetiva entre uma competência e um mercado, na qual os agentes da fala se defrontam a partir de posições diferenciadas, como portadores desiguais de capital lingüístico e de outras espécies de capital. " $A$ linguagem deve, assim, parte de suas propriedades à antecipação prática da reação que ela é capaz de suscitar, reação que depende do próprio discurso e de toda pessoa social daquele que o pronuncia. A forma e o conteúdo do que pode ser dito e do é dito dependem da relação entre um habitus lingüístico que se constitui na relação com um campo de um determinado nivel de aceitabilidade. ${ }^{48}$

Para Bourdieu, a linguagem só pode ser compreendida, na sua profunda articulação com o mercado, na qual ela insere e adquire significado. Na condição de bem simbólico, de vigoroso poder, é objeto de acirradas disputas, nas quais o capital lingüístico e simbólico nem sempre detém um maior valor, outras espécies de capital marcam a sua presença, na medida em que é "toda a pessoa social que enuncia". Esta visão da linguagem, vista sob a ótica do mercado lingüístico, ganha em Habermas uma outra conotação, que teremos a oportunidade de desenvolver a seguir.

Bourdieu e Habermas: Um Esforço Comparativo

Antes de iniciarmos uma análise comparativa entre Bourdieu e Habermas, acerca das questōes da linguagem, consideramos profícuo assinalarmos algumas identidades e dissemelhanças que informam os seus modos de pensar e que poderão de algum modo ser úteis à compreensão de suas visões específicas da linguagem e sua utilização, que nos interessa de maneira especial.

Uma primeira identidade, de caráter geral, diz respeito à postura assumida no debate com as diversas correntes do pensamento social. Ambos se propõem a romper com oposições estéreis de esco-

${ }^{48}$ Idem, ibidem, p. 172.

Temáticas, Campinas, 1(1/2):189-227, jul./dez. 1993. 
las e estabelecer um diálogo franco e aberto com seus interlocutores, buscando extrair deles possíveis contribuições. Esta ousadia fez atrair para ambos o injusto rótulo de ecléticos, que definitivamente não faz juz ao rigor conceitual dos dois.

A segunda identidade que pode ser registrada entre Bourdieu e Habermas é quanto as suas proposições afins de analisar e superar as dicotomias do pensamento social moderno, entre o objetivismo e o subjetivismo, o que, em algum momento, faz com que ambos se deparem com os mesmos interlocutores.

Habermas afasta-se das perspectivas fenomenológicas, onde tudo é explicado a partir da intencionalidade dos atores e do sentido conferido às suas ações, como também das visões sistêmicas, onde tudo é explicado a partir de conexões de ações funcionais, nas quais os atores não aparecem, buscando, na articulação dessas duas dimensões uma saída, preservando como momento insubstituível da análise às esferas do "sistema" e do "mundo de vida". No primeiro caso, significa ser capaz de compreender a gestação intersubjetiva de sentido, que realizam os participantes das interações (perspectiva interna de análise). No segundo caso, significa assumir o papel de um observador exterior, que tem diante de si conexōes de ação não pretendidas, através do entrelaçamento funcional (perspectiva externa de análise).

A perspectiva analítica, que articula como momento de um processo único as dimensões do sistema e do mundo de visa, é o modo habermasiano de superar a filosofia da consciência ou do sujeito, inclusive nas suas formulações mais recentes do individualismo metodológico, e rejeitar as visōes estruturalistas que ignoram a ação dos agentes como elemento integrante da análise.

Um último elemento a ser registrado, em termos das aproximações entre os dois autores, é a afirmação do conhecimento como sendo pautado por interesses. Embora não tenhamos reproduzido neste trabalho as reflexões de Bourdieu sobre o campo científico e o

Temáticas, Campinas, 1(1/2):189-227, jul./dez. 1993. 
papel do sociólogo, em especial, é vastamente conhecido o questionamento de Bourdieu à idéia do conhecimento científico desinteressado e o desconforto promovido pelas suas críticas ao funcionamento do campo científico. ${ }^{49}$

No seu trabalho Conhecimento e interesse, Habermas postula a íntima conexão entre a produção do conhecimento e os interesses aos quais se vincula. A tese central do trabalho, como afirma Heck, é que "todo o conhecimento é posto em movimento por interesses que o orientam, dirigem-no, comandam-no". ${ }^{50}$

Afora estas e outras aproximações possíveis de serem traçadas, há profundas diferenças entre eles. Nos limitamos a enunciar uma de caráter mais geral, dado que é nosso interesse nos determos em observações mais acuradas no campo específico da análise da linguagem. A referência que fazemos aqui é propriamente aos seus modos de pensar. A condição de filósofo de um e sociólogo do outro certamente faz diferença na forma de abordar as questões. No nosso entendimento, isso tem repercussões na formulação de suas teorias, que assume em Habermas um caráter predominantemente formal, procedimental e em Bourdieu um caráter histórico-institucional.

A partir dessas considerações, talvez possamos compreender de forma mais adequada os trabalhos desses autores no enfrentamento da temática da linguagem. De maneira o mais breve possível, levantaremos alguns pontos centrais da análise habermasiana afim de estabelecermos com mais propriedade uma análise comparativa com o pensamento de Bourdieu, já exposto.

Como tivemos a oportunidade de registrar, Habermas busca construir uma teoria social capaz de ultrapassar as totalidades vagas, o holismo e as explicações de caráter estrutural-funcional, sem, contudo, pautar a sua análise no plano do indivíduo. O social só é compreensível como social. Nesse sentido, os sujeitos só emergem em

${ }^{49} \mathrm{Idem}$, "O campo científico", in Bourdieu, p. 123.

${ }^{50} \mathrm{HECK}$, José, "Introdução", in HABERMAS, J., Conhecimento $e$ interesse, Ed. Guanabara, Rio de Janeiro, 1987, p. 07.

Temáticas, Campinas, 1(1/2):189-227, jul./dez. 1993. 
processo de interação social, que são a um só tempo a condição de possibilidade da sua existência e esfera privilegiada de intervenção.

Nessa perspectiva, Habermas traz o ator de volta para o centro da explicação social, mas o redimensiona. Esse ator só é compreensível a partir da sua inserção num contexto interativo linguistificado, nesse sentido, como um sujeito capaz de linguagem e, portanto, detentor potencial de capacidade crítica, que se forma à medida que se realiza a interação. Esta nos parece uma outra diferença significativa com Bourdieu, que desconsidera a capacidade crítica dos agentes e visualiza a linguagem, unicamente como campo de disputa e não como instrumento emancipatório.

Na Teoria da ação comunicativa, Habermas postula a indissociabilidade das dimensões do sistema e do mundo de vida para uma teoria social que se pretenda explicativa. ${ }^{51}$ É somente no mútuo entendimento dessas esferas e de suas relações, bem como através da compreensão do processo de diferenciação das racionalidades que lhes subjaz e constitui, que se colocariam as ciências sociais à altura do desafio de compreender as sociedades modernas e as suas patologias: "No podemos compreender el carater del mundo vital a menos que compreendamos los sistemas sociales que lo configuran, y no podemos compreender los sistemas sociales a menos que veamos como surgen a partir de la sintesis del sistema e de las orientaciones del mundo vital se integra con la delineación que hace Habermas de las diferentes formas de racionalidad y racionalización: la racionalidad de los sistemas es un tipo de racionalidad deliberado-racional, la racionalización del mundo vital es una racionalidad comunicativa. $" 52$

$\mathrm{O}$ mundo de vida está sempre presente em qualquer processo interativo. Ele se configura como um "depósito de auto-evidências

${ }^{51}$ HABERMAS, Jürgen, Teoria de la ación comunicativa, vol.II, Taurus Ediciones, 1988.

${ }^{52}$ BERNSTEIN, Richard, "Introducción", in BERNSTEIN, R. (org.), Habermas y la Modernidad, Cátedra Ediciones, Madrid, p. 46.

Temáticas, Campinas, 1(1/2):189-227, jul./dez. 1993. 
e convicciones incuestionadas" ${ }^{53}$ Nesse sentido, não pode ser problematizado na sua totalidade, mas apenas podem ser tematizados "fragmentos". do mundo de vida que se evidenciam num contexto de ação.

Para Habermas, na prática comunicativa cotidiana não existem situações inteiramente desconhecidas, dado que todas as situaçōes emergem de um mundo de vida frente ao qual os participantes não podem estabelecer uma posição extra-mundana: "los agentes comunicativos se mueven siempre dentro del horizonte qui es su mundo de la vida, de el no pueden salirse ${ }^{5 .}{ }^{54}$ É dele que extraem as conviç̧ões e esquemas cognitivos e nele são estabelecidas as formas de socialidade.

Constitui, pois, o lugar transcendental possibilitador do entendimento, onde falante e ouvinte se encontram e estabelecem pretensões de validade com relação ao mundo objetivo, social e subjetivo, podendo estabelecer críticas e fundamentos dessas pretensões com vistas a um acordo. Nesse sentido é que se pode afirmar que "las estructuras del mundo de la vida fijam las formas de la intersubjetividad del entendimiento possible ${ }^{.55}$

Habermas, ao se situar no âmbito da filosofia da linguagem, incorpora o conceito de mundo de vida, redefinindo-o em termos mais amplos, abrangendo não só a esfera da consciência, mas o contexto da comunicaçāo lingüística, colocando em primeiro plano a intersubjetividade. Para Habermas, a concepção do mundo de vida reduzida em termos culturalistas (vertentes fenomenológicas da filosofia analítica e da hermenêutica), restrita aos aspectos do entedimento, se incapacita a perceber que a ação comunicativa é a um só tempo um processo de entendimento de interação social e de socialização. Ao se entenderem sobre algo no mundo, os agentes comunicativos participam simultaneamente de interações através das quais confir-

\footnotetext{
${ }^{53}$ HABERMAS, Jürgen, op. cit., p. 176.

${ }^{54}$ Idem, ibidem, p. 179.

${ }^{55}$ Idem, ibidem, p. 179.
}

Temáticas, Campinas, 1(1/2):189-227, jul./dez. 1993. 
mam e renovam o seu pertencimento a grupos sociais e a sua própria identidade: "Bajo el aspecto funcional de entendimiento, la acción comunicativa sirve a la tradición y a la renovación del saber cultural; bajo el aspecto de coordinación de la acción a la integración social y a la creación de solidaridad; bajo el aspecto socialización, finalmente, serve a la formación de identidades personales. ${ }^{256}$

A esses processos de reprodução cultural, integração social e socialização, correspondem os três componentes estruturais do mundo de vida, que são a cultura, a sociedade e a personalidade. Cultura vem a ser o estoque de saber da comunidade, o "celeiro", que contém os conteúdos semânticos da tradição, que fornecem aos agentes comunicativos os modos interpretativos necessários à convivência social. A sociedade é constituída pelos ordenamentos sociais legítimos, mediante os quais os membros da comunidade regulam o seu pertencimento a grupos sociais, garantindo solidariedade. Finalmente, a personalidade é um conjunto de competências, que convertem um sujeito, num ser capaz de linguagem e ação, ou seja, que o capacita a participar dos processos de entendimento, afirmando a sua própria identidade. ${ }^{57}$

Para Habermas, a sociologia compreensiva "dissolve" a sociedade em mundo de vida e passa a percebê-la, a partir de uma perspectiva interna, subestimando aspectos exteriores, passíveis de agir influentemente sobre o mundo cultural da vida, numa perspectiva ingênua, onde a cultura se auto-interpreta. São as falácias de um "idealismo hermenêutico", 58 que tem como seu reverso um descritivismo metodológico, incapaz de ultrapassar a "descrição densa", ou seja, a reformulação de um saber mais ou menos trivial. Para se aceitar a concepção da sociedade como mundo de vida seria necessário, segundo Habermas, aceitar três "ficções" que marcam toda a socio-

\footnotetext{
${ }^{56}$ Idem, ibidem, p. 196.

${ }^{57}$ Idem, ibidem, p. 197.

${ }^{58}$ WELLMER, Albret, op. cit.
}

Temáticas, Campinas, 1(1/2):189-227, jul./dez. 1993. 
logia compreensiva: a autonomia dos sujeitos, a independência da cultura e a transparência da comunicação.

Essas noçōes caem por terra, ao identificarmos que a sociedade não corresponde apenas ao mundo de vida. Ao atuarem com vistas ao entendimento, os agentes comunicativos não têm suas ações coordenadas exclusivamente através de processos comunicativos, mas também mediante conexões funcionais não pretendidas, e que na maioria das vezes não se dão a conhecer no horizonte da prática cotidiana.

Nesse sentido, faz-se necessário distinguir entre integração social e integração sistêmica. A integração social se radica num consenso assegurado normativamente ou mediante um consenso comunicativamente estabelecido. A integração sistêmica se funda num controle não normativo de decisōes particulares, carentes subjetivamente de coordenação. ${ }^{59}$

Entender a sociedade exclusivamente como integração social (Husserl, Wittgenstein) significa situarmo-nos no âmbito da estratégia conceitual que concebe a sociedade como mundo de vida e compreender as interações como fundadas nas tradições culturais intersubjetivamente partilhadas, o que implica que a análise científica se liga à perspectiva interna dos membros dos grupos sociais, obrigada que está a vincular hermeneuticamente a sua compreensão à interpretação dos participantes.

Por outro lado, ao identificarmos a integração da sociedade somente como integração sistêmica (Parsons, Luhman) vinculamo-nos à estratégia conceitual que apresenta a sociedade como modelo de um sistema auto-regulado, ou seja, estruturado a partir de conexões de ações não pretendidas, através do entrelaçamento funcional de seqüências de ações, o que determina um eixo analítico, ligado à perspectiva externa de um observador.

Para a teoria do sistema, a integração social e a sistêmica são consideradas equivalentes funcionais, o que a impede de detectar os

${ }^{59}$ HABERMAS, Jürgen, op. cit. p. 167.

Temáticas, Campinas, 1(1/2):189-227, jul./dez. 1993. 
custos, ao nível do mundo vital, da complexificação sistêmica. É somente a partir da assunção do paradigma da racionalidade comunicativa, que se torna manifesta a reação destrutiva dos subsistemas autonomizados sobre o mundo de vida racionalizado, submetido a uma violência estrutural, exercida mediante a restrição sistemática da comunicação, que promove a colonização do mundo de vida pelos mecanimos sistêmicos.

$\mathrm{O}$ que Habermas apreende como patologia, para Bourdieu configura-se simplesmente como o mecanismo de funcionamento das relações interativas, que se configura na forma de um mercado lingüístico. Habermas vê de um ponto de vista crítico o que Bourdieu visualiza, de forma "naturalizada". A diferença radical de percepção entre eles advém de seus propósitos analíticos, claramente diferenciados, de reconhecimento dos mecanismos de reprodução social, no caso de Bourdieu e da perspectiva emancipatória, no caso de Habermas.

Desta forma, Bourdieu visualiza de forma indiferenciada, princípios de integração, considerados concorrentes na proposição habermasina. A configuração das relações interativas nos moldes de um "mercado lingüístico" é exatamente a expressão da invasão sistêmica na esfera da ação comunicativa, que deixa de ter a linguagem como medium do entendimento, para pautar-se em torno de meios de integração sistêmicos como o dinheiro e o poder. É nesse processo, designado por Habermas de colonização do mundo de vida, que encontra-se a base fundante das patologias modernas.

Para Habermas, trata-se, na modernidade, de perceber o desenvolvimento parcializado de um tipo de razão, que ele qualifica como instrumental e que reduz as dimensões da racionalidade a uma ação com respeito a fins e que se configura como razão manipulatória e opressora. É este, precisamente, o seu ponto de ruptura mais significativo com Bourdieu, cuja proposta teórica fundamenta a ação social, como uma ação estratégica, definindo-a do ponto de vista dos interesses. A sociologia de Bourdieu, radicada numa razão

Temáticas, Campinas, 1(1/2):189-227, jul./dez. 1993. 
instrumental, compreende a ação humana como tendo um caráter manipulatório e dominador. Em tal concepção, não há lugar para a gratuidade ou para a discussão racional crítica, tudo é reduzido a relações de poder.

O que Habermas vai tentar demonstrar é que esta é apenas uma dimensão da racionalidade, que se apresenta, na modernidade, como hegemônica. A racionalidade, numa perspectiva mais ampla, comporta uma outra dimensão, que foi inclusive reprimida e sistematicamente obscurecida: a razão comunicativa, que se refere à dimensão interativa do homem na sua relação com a alteridade.

$\mathrm{O}$ sentido da racionalidade, nesse ponto de vista, explicita a relação social entre pelo menos dois atores, onde através da argumentabilidade, se chega a uma posição de consenso, onde se faz possível ultrapassar o nível da cotidianidade, onde impera o consenso ingênuo - não problematizado, mas a qualquer hora problematizável (esfera da socialidade fática), para o consenso crítico fundamentado em razões (esfera discursiva), âmbito da ação comunicativa.

Ao lado do mundo objetivo emerge o mundo social, onde não está em jogo apenas um comportamento cognitivo, mas motivacional, o que envolve necessariamente duas posturas: objetivante e performativa. Dessa forma, o conhecimento ganha uma nova dimensão, ou melhor, resgata uma dimensão historicamente reprimida, "colonizada", rompendo as amarras de um saber manipulatório e dominador e se abre à discussão da validade de suas proposições, através de um processo argumentativo. $O$ conhecimento se constitui dentro de um processo mútuo de compreensão, mediado linguisticamente, tendo como elemento estruturador, não a postura de um sujeito manipulador do mundo e do "outro" da interação, mas a intersubjetividade dos que participam de uma relação discursiva.

É essa mudança de paradigma que vai possibilitar a Habermas dialogar com as duas grandes correntes filosóficas deste século: a fenomenologia-existencial e a empírico-lógico-analítica, apropriando-se dos seus resultados mais significativos. A con-

Temáticas, Campinas, 1(1/2):189-227, jul./dez. 1993. 
vergência dessas correntes se dá em torno da superação da filosofia da consciência, pela descoberta da linguagem como um novo paradigma, a partir do qual são reformulados os problemas fisolóficos ${ }^{60}$

A linguagem vai ser compreendida como um processo de comunicação intersubjetivo, cuja unidade fundamental não é a proposição, mas o proferimento, ou seja, a proposição inserida no processo normal de interação lingüística. Dessa forma, transfere-se o eixo da investigação da racionalidade cognitiva, para a racionalidade comunicativa.

Habermas recupera, na sua teoria da ação comunicativa, elementos da teoria da linguagem do segundo Wittgenstein e a teoria dos atos de fala de Austin. No primeiro caso, incorpora a tese de que falar é agir socialmente, constitui uma forma de vida e de seguimento a regras gestadas socialmente. No segundo, assume a tese de que falar coisas significa fazer proferimentos que estabelecem relações sociais. Nesse sentido, sua teoria ultrapassa a esfera da lingüística e se consubstancia como pragmática.

A teoria da competência comunicativa entende que todo ato da fala é composto de uma dupla estrutura: uma frase performativa (que cria uma relação subjetiva) e uma frase proposicional (que expressa o objetivo sobre o qual se fala). O entendimento pressupõe um sistema comum de referência, que permite aos participantes se entenderem sobre algo. Este sistema comum diz respeito ao mundo objetivo, social e subjetivo, ao qual corresponde a tríplice função da linguagem: de apresentação, de interpretação e de expressão. É a partir desse sistema de referência, que quem fala se refere por seus proferimentos a algo objetivo, normativo ou subjetivo. ${ }^{61}$

Os participantes da interação levantam pretensões, em princípio demonstráveis, que apresentam uma criticidade imanente. Podemos citar quatro pretensões de validade reivindicadas: que o enunciado é

${ }^{60}$ HERRERO, Xavier, "Racionalidade comunicativa e modernidade", in Revista Síntese, $\mathrm{n}^{\circ} \cdot 37,1986$, p. 17.

${ }^{61}$ Idem, ibidem, p. 18.

Temáticas, Campinas, 1(1/2):189-227, jul./dez. 1993. 
verdadeiro, que a interação é correta em relação as normas vigentes, que a expressão proferida é veraz, ou seja, exprime corretamente o que se pensa e por último que o sistema simbólico utilizado é passível de ser compreendido. "A racionalidade da ação comunicativa se baseia em atos de fala, que levantam pretensões de validade que podem ser criticadas e fundamentadas sobre a força do melhor argumento. $\$ 62$

Trata-se de uma situação ideal de diálogo, não realizável empiricamente ${ }^{63}$ que se caracteriza pela ausência de qualquer forma de mutilação sistemática da comunicação, onde prevalece sempre a força do melhor argumento, o que significa igualdade de condições em todos os níveis para os participantes do processo discursivo. Essa situação ideal antecipada tem como pressuposto a antecipação de uma forma ideal de vida, marcada pelos ideais de liberdade e justiça. ${ }^{64}$

Esta formulação vai ser objeto de uma crítica explícita de Bourdieu, que acusa Habermas de promover uma idealização das relações interativas, que teria por efeito eliminar das relações de comunicação as relações de força, e que estaria expresso na sua utilização a-crítica do conceito de força ilocucionária. "L'idealisation (parfaitement visible dans le recours à des notions telles qui 'matrise des universaux constitutifs du dialogue' ou 'situation de parole, determinée par la subjetivité pure') a pour effet d'évacuer pratiquement des rapports de communication les rapports de force qui s'y accomplissent sous une forme transfigurée: à preuve, l'emprunt non critiqué de concepts comme celui d'illocutionary force qui tend à placer dans les mots - et non dans les conditions institutionelles de leur utilisation - la force des mots. ${ }^{\infty 65}$

${ }^{62}$ Idem, ibidem, p. 19.

${ }^{63}$ SIEBENEICHLER, Flávio, Jürgen Habermas: razão comunicativa $e$ emancipação, Tempo Brasileiro, Rio de Janeiro, 1989.

${ }^{64}$ Idem, ibidem, p. 107.

${ }^{65}$ BOURDIEU, Pierre, Ce que parle veut dire, p. 25.

Temáticas, Campinas, 1(1/2):189-227, jul./dez. 1993. 
$\mathrm{Na}$ verdade, preocupação norteadora de Habermas é a construção racional do consenso político, a questão da sua legitimidade, nesse sentido, ele está muito menos preocupado com conteúdos, do que com procedimentos. Nessa perspectiva, Bourdieu é injusto à Habermas na sua cobrança, até porque a preocupação sistemática com mecanismos procedimentais, que informa a teoria habermasiana, na busca de garantir um processo de discussão racional legítima, só tem sentido a partir do reconhecimento de que, na atualidade isso ocorre, na medida em que esta possibilidade é obstruída pela invasão dos mecanismos sistêmicos: dinheiro e poder, na esfera da interação humana. Por outro lado, Habermas é contundente nas suas críticas ao campo da lingüística, afirmando uma compreensão pragmática da linguagem, onde o proferimento tem maior significado do que a proposição.

Uma outra crítica freqüentemente dirigida a Habermas, e que certamente Bourdieu compartilharia, é quanto à postulação da competência universal dos agentes sociais. Mais uma vez o enfoque habermasiano dá ênfase aos elementos procedimentais, que possibilitam a fala, buscando assinalar a competência comunicativa, enquanto condição de possibilidade da formulação dos discursos. Bourdieu, ao voltar a sua análise para as situações concretas da fala, que Habermas abstrai, apresenta os sujeitos como tendo competências articuladas a partir da sua posição social, questionando, portanto, a possibilidade de competências universais.

Um último ponto, que gostaríamos de considerar especialmente, dadas as nossas preocupações específicas de análise, refere-se ao modo de conceber a cultura que em ambos os autores, parece ser vista de modo insuficiente. No caso de Habermas, a cultura é vista de um ponto de vista estático, como depósito de conteúdos semânticos das tradições, modelos a que se reportam os agentes no exercício da convivência social. No caso de Bourdieu, a cultura é vista de um ponto de vista mais dinâmico, como constituidora de práticas. Contudo, fica subsumida nas relações de poder,

Temáticas, Campinas, 1(1/2):189-227, jul./dez. 1993. 
como afirma com propriedade Canclini: "si bien la obra de Bourdieu es una sociologia de la cultura sus problemas centrales non son culturales" ${ }^{66} \mathrm{Na}$ verdade, Bourdieu politiza as relações culturais, reduzindo-as a expressão de relações de poder. Nesse sentido, embora reconhecendo o mérito inegável de Bourdieu, ao evidenciar tais relações de força, consideramos o seu enfoque analítico, centrado nessas relações, como restrito e empobrecedor.

${ }^{66}$ CANCLINI, Néstor, op. cit., p. 09.

Temáticas, Campinas, 1(1/2):189-227, jul./dez. 1993. 